\title{
The Role of Information Technology (Smart School Implementation) in Academic Achievement of the Elementary Students in Bandar Khamir County
}

\author{
Jasem Solaymani \\ A Graduate Student in Education Management at Qeshm International Branch, Islamic Azad University \\ Mahnoosh Abedini (PhD)
}

Assistant Professor of Farhangian University Hormozgan, Bandar Abbas, Iran

\section{Doi:10.5901/mjss.2016.v7n2s2p87}

\begin{abstract}
This research was conducted to examine the role of IT (smart school implementation) in academic achievement of the primary school students of Bandar Khamir. The target statistical population included all the elementary students (5864, in total) of the mentioned county in the school year 2014-2015. Of this population, using multi-stage sampling, 362 students were selected whose grades for 5 percent of the subject matters natural sciences, mathematics, Farsi spelling, Farsi writing, and Farsi Reading were collected and analyzed. Half of the sample group had received training on the use of IT and smart schooling tools, while the other half kept using the traditional learning methods. The sample group was made up of 55.2 percent boys and 44.8 percent girls. Given that the mean scores of two independent groups were to be compared, student's $t$-test was applied to test of the research hypotheses. All of the hypotheses were supported by the testing results, suggesting that mean scores of the students trained for the use of IT and smart learning tools were greater than the students who kept using the traditional learning methods.
\end{abstract}

Keywords: smart school implementation, academic achievement, elementary school

\section{Introduction}

In the present era which is known as the era of transition from the post-industrial society to the information society, information and knowledge are naturally expected to be considered as the most crucial assets to human societies. The important characteristic of the IT phenomenon is that it facilitates and enhances both the relationship of human with human and human with nature. Information technology, due to its transformability and the strong influence that it has in promotion of education, culture, economy, national security, and globalization, and resolving the problems existing in the traditional ways of information supply, is regarded as one of the most dynamic and most debatable field of science and technology (Jaschik, 2010). Hence, understanding its effect size on the one side, and the ways and mechanisms through which it may exercise a better influence in education, especially the education of children and adolescents on the other side, is of high importance (Duman, 2007). Now, considering the IT capacity and the various functions it actually fulfills, as mentioned above, the current study primarily seeks to find an answer to the question as whether the new information and communication technologies (ICT) do have an impact on academic achievement of the elementary school students.

\section{Literature Review}

Information technology is the process of collection, selection, processing, storage, and application of information in desired areas and their transfer via multimedia computers in a way that eventually would result in design and choice of teaching materials (subject matters), and teaching-learning process is managed as a network of learners, teachers, experts, educational designers, and computer technocrats where the type of the IT-based educational space is dynamic, real-time, and collaborative with no temporal and spatial limitations, and the learners themselves adjust their learning tempo (Ebrahimzadeh, 2010).

Academic achievement signifies the amount of the individual school learning so that the learned quantity could be studied in terms of two general categories of the factors pertaining to individual differences and family life and the factors pertaining to school and education system. It refers to manifestation of the student's academic (study) situation, and this manifestation may indicate the grade for a period, mean grades in one single subject matter for a set of periods, or mean grades for different periods (Çelik and Keski, 2009). 


\section{Methodology}

This is an applied research which was conducted based on a correlational, descriptive survey design. The statistical population included all the elementary students (5864, in total) of Khamir County in the school year 2014-2015. From among these students, using multi-stage sampling and Cochran's sample size formula, 362 students were finally selected. The required information was obtained from two standard questionnaires with query items designed in Likert 5point scale.

\subsection{The conceptual model}

Based on the theoretical findings in the research literature, the following conceptual model is drawn.

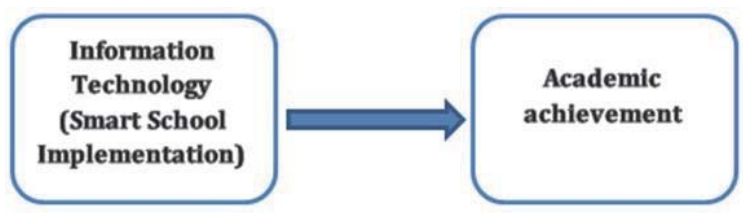

Figure 1 - The conceptual model of the relationship between information technology and student academic achievement

\subsection{Research Hypotheses}

\subsubsection{The main hypothesis}

The use of IT has effect on academic achievement of the elementary students.

\subsubsection{The sub-hypotheses}

1. There is a significant relationship between use of IT and mean scores of the students (in the experimental and the control groups) in natural sciences.

2. There is a significant relationship between use of IT and mean scores of the students (in the experimental group and the control groups) in mathematics.

3. There is a significant relationship between use of IT and mean scores of the students (in the experimental group and the control groups) in Farsi spelling.

4. There is a significant relationship between use of IT and mean scores of the students (in the experimental group and the control groups) in Farsi writing.

5. There is a significant relationship between use of IT and mean scores of the students (in the experimental group and the control groups) in Farsi reading.

\section{Results}

The data analysis was performed in the SPSS environment. Before test of the hypotheses, using Kolmogorov-Smirnov (K-S) test the data were checked to see if they were normally distributed. The results of the K-S test are presented in table 1.

Table 1 - The result of Kolmogorov-Smirnov test of normality

\begin{tabular}{lcc}
\hline & Information technology & Academic achievement \\
\hline $\mathbf{N}$ & 362 & 362 \\
Mean & 2.9051 & 2.8865 \\
Std. Deviation & 0.67718 & 0.70273 \\
Kolmogorov-Smirnov Z & 2.077 & 3.515 \\
Asymp. Sig & 0.115 & 0.113 \\
\hline
\end{tabular}


As is seen in table 1, the Sig value for both variables is greater than the predefined significance level of 0.05 and accordingly, the null hypothesis $\left(\mathrm{H}_{0}\right)$ on normal distribution of the variables is confirmed. Next, for test of the main hypothesis, student's t-test was performed for two independent samples the result of which is presented in the table below.

Table 2 - The results of t-test for the first sub-hypothesis

\begin{tabular}{|l|c|c|c|c|c|c|}
\hline Teaching method & $\mathbf{N}$ & Mean & St. Dev. & t-value & Df & p \\
\cline { 1 - 4 } Traditional & 362 & 18.80 & 1.44 & \multirow{2}{*}{6.32} & 281.58 & 0.00 \\
\hline IT-based & 362 & 18.57 & 0.80 & & \\
\hline
\end{tabular}

Given $t=6.32$ at $p=0.000$ in table 2, the first sub-hypothesis is accepted. That is to say, the mean science scores of the students who were trained in using IT for learning are significantly greater relative to their peers using traditional method of learning.

Table 3 - The results of t-test for the second sub-hypothesis

\begin{tabular}{|l|c|c|c|c|c|c|}
\hline Teaching method & $\mathbf{N}$ & Mean & St. Dev. & t-value & Df & p \\
\cline { 1 - 4 } Traditional & 181 & 18.03 & 1.53 & \multirow{2}{*}{8.17} & 270.76 & 0.00 \\
\hline IT-based & 181 & 19.08 & 0.80 & & & \\
\hline Leven's test: $\mathrm{F}=127.28 \mathrm{P}=0.000$
\end{tabular}

With $t=8.17$ and $p=0.000$ in table 3 , the second sub-hypothesis is accepted. That is to say, the mean mathematics scores of the students who were trained in using IT for learning are significantly greater relative to their peers using traditional method of learning.

Table 4 - The results of t-test for the third sub-hypothesis

\begin{tabular}{|l|c|c|c|c|c|c|}
\hline Teaching method & $\mathbf{N}$ & Mean & St. Dev. & t-value & Df & p \\
\hline Traditional & 181 & 17.79 & 1.35 & \multirow{2}{*}{8.76} & 338.47 & 0.00 \\
\hline IT-based & 181 & 18.90 & 1.05 & & & \\
\hline
\end{tabular}

With $t=8.76$ and $p=0.000$ in table 4 , the third sub-hypothesis is confirmed. That is to say, the mean spelling scores of the students who were trained in using IT for learning are significantly greater relative to their peers using traditional method of learning.

Table 5 - The results of t-test for the fourth sub-hypothesis

\begin{tabular}{|l|c|c|c|c|c|c|}
\hline Teaching method & $\mathbf{N}$ & Mean & St. Dev. & t-value & Df & $\mathbf{p}$ \\
\hline Traditional & 181 & 17.56 & 1.54 & \multirow{2}{*}{10.35} & \multirow{2}{*}{284.74} & 0.00 \\
\cline { 1 - 4 } IT-based & 181 & 18.92 & 0.87 & & \\
\hline Leven's test: $\mathrm{F}=12.13$ & $\mathrm{P}=0.000$ \\
\hline
\end{tabular}

With $t=10.35$ and $p=0.000$ in table 5 , the fourth sub-hypothesis is accepted. That is to say, the mean Farsi writing scores of the students who were trained in using IT for learning are significantly greater relative to their peers using traditional method of learning.

Table 6 - The results of t-test for the fifth sub-hypothesis

\begin{tabular}{|l|c|c|c|c|c|c|}
\hline Teaching method & $\mathbf{N}$ & Mean & St. Dev. & t-value & Df & P \\
\hline Traditional & 181 & 18.55 & 1.22 & \multirow{2}{*}{3.35} & 339.05 & 0.00 \\
\hline IT-based & 181 & 18.93 & 0.89 & & \\
\hline Leven's test: $\mathrm{F}=12.13 \mathrm{P}=0.000$ \\
\hline
\end{tabular}


Given $t=3.35$ and $p=0.000$ in table 5 , the fifth sub-hypothesis is accepted. That is to say, the mean Farsi reading scores of the students who were trained in using IT for learning are significantly greater relative to their peers using traditional method of learning.

\section{Conclusion}

Considering the obtained results from test of the hypotheses, it can be concluded that the use of IT has positive effect on academic achievement of the students, raising their mean grades. These results are perfectly consistent with the findings of other similar studies, including those of Kimmins (1995) and Zimmerman (1991). Their research highlighted the end of the graphical limitations of the paper- and pen-based methods by IT which allows greater accuracy and freedom to study issues within a smart setting. In this setting, viewing properties of geometrical shapes has become more possible, the matters can be seen more real than what was seen in the past, allowing to further develop one's geometrical skills. The results were also consistent with the research findings of Martin Root and Adams (2004). IT motivates them in the course of learning, since during the learning they are assigned a role to play, and in doing so, it makes learning attractive for them and finds in them the incentive to work. Therefore, its application in education should be taken into consideration. Similar results were found by Fletcher (1990), Colic (1994), Kachala (1996), and Louis and Maize (1991) as well. Considering the IT crucial role in discovering innovative and creative ways of approaching the issues and producing novel ideas, it provides the assumed information and communication technology (ICT) allowing students to achieve selfregulation and autonomy, and making them capable of broad and flexible thinking and decision making with free choice to explore and discover new solutions. Therefore, its application in education is necessary for stimulating innovation and creativity in students.

\section{Suggestions}

In this section, given the IT impact on academic achievement of students, the following suggestions are made to officials and directors of the Education Office:

1. Adjusting the educational policymaking, planning, and decision making system with the new changes regarding cultural, political, and educational development;

2. Continuous improvement of the Education Office's employees in the form of reassessment with the purpose of promoting skilled employee's quality and efficacy for the use of ICT and smart school implementation in education;

3. Selection of the suitable workforce for education within the framework of implementing a long-term plan based on the Education Office new policies;

4. Providing the ground for active and dynamic engagement of students in the educational activities using novel and innovative approaches;

5. Attracting public participation and utilizing the native and local forces in the smart school implementation project;

6. Paying due attention to new ICT developments and effective use of the existing equipment;

7. Profiting from international and regional cooperation and exchange of constructive experiences regarding IT applications; and

8. Adjusting the education structure and content to the student's real needs and producing its corresponding electronic content.

\section{References}

Armitage,susan and o geary,Rose(2003) E-gearning series;Acuide for learning technologist. Heslington: LTSN Generic Centre.

Bayradtar,S.(2001)A meta-analysis on the effectiveness of computer-assisted Instruction in science education (Doctoral Dissertation ,ohio university,2000). Dissertation Abstracts International. 61(01),

Çelik, Levent, Keskin, Murta. (2009). The effects of the primary class teachers` information technology literacy skill level on students` achievement: the case of Afyonkarahisar, Procedia Social and Behavioral Sciences 1, 1167-1171.

Clements,M.M\&Elerton,F.N.(1996):Mathematics Education Regional Office for Asia and the Pacific.

Dellas.M(1991). Effects of creativity thinking: Defensiveness and intelligence of divergent.

Dillon, J.T (1994) Classroom Environments. The International Encyclopedia of Education, PP807-811.

Dubinsky,E.\&Tall,D.(1991);Advanced Mathematical Thinking And the Computer,inTall,D.(ed.)Advanced Mathematical Thinking, Kluwer, Dordrecht, pp. 231-248. 
Duman, A. (2007). Okullarda Biliúim Teknolojisinden Etkili Yararlanmada Okul Y|netimi AoÕsÕndan KarúÕlaúÕlan Sorunlar (ElazÕ ili |rne-ii), YayÕnlanmamÕú Yksek Lisans Tezi, FÕrat hniversitesi, Sosyal Bilimler Enstits, ElazÕ.

Ebrahimzadeh, lessa (2006), "The Information Technology Based Education: A Conceptual Inquiry," Quarterly Journal of Peik-e-Nour, $4(4)$

Jaschik, S. (2010). Educes constituent groups online and face to face discussions on topics of interest. Retrieved from http://www.edu cause.edu.

Kuller, R.,Lindsten, C. (1992) Health and behavior of children classrooms with and without windows. Journal of Environmental psychology.

Kasakowsk;,j(1998)the Benefits of information Technology ERIC clearing house on information and technology syracuse.Steffen,J.\& Hansen,G(1987). EFFect of Computer-ussisted inoctruction on development of Cognitive and psychomotor learining in bowling. Journal of teaching in physical Education ,6183-191.

Tall,D.(1992);Students Difficulties in Calculus. Proceedings of Workin Group 3 on students Difficulties in Calculus ,ICME7,1992,Quebec, Canada, pp.13-28,www.warwick.ac.uk/staff/David.tall/pdfs. 